\title{
NITRIC OXIDE METABOLISM IN PATIENTS WITH COMMUNITY- ACQUIRED PNEUMONIA ASSOCIATED WITH CORONARY HEART DISEASE AND THE POSSIBILITY OF ITS MEDICAMENTOUS MANAGEMENT
}

DOI: 10.36740/WLek202008122

\author{
Mykola M. Ostrovskyy', Oleksandr I. Varunkiv' ', Lilia Dm. Todoriko², Iryna O. Savelikhina', \\ Mariana 0. Kulynych-Miskiv' ${ }^{1}$, Alla B. Zuban' ${ }^{1}$, Olha B. Molodovets' ${ }^{1}$, Kseniia M. Ostrovska' \\ 'IVANO-FRANKIVSK NATIONAL MEDICAL UNIVERSITY, IVANO-FRANKIVSK, UKRAINE \\ 2BUKOVINIAN STATE MEDICAL UNIVERSITY, CHERNIVTSI, UKRAINE
}

\begin{abstract}
The aim: To assess the metabolic by-products of nitric oxide in peripheral blood before and after the medicamentous management in patients suffering from community-acquired pneumonia associated with coronary heart disease.

Materials and methods: We have examined 102 patients with community-acquired pneumonia aged from 50 to 65 years, of which 58 patients were diagnosed with coronary heart disease (CHD). The complex treatment of patients with coronary heart disease was supplemented by the additional use of tivortin aspartate, which was taken orally with food at the dose of $5 \mathrm{ml}(\mathrm{gg}) 3$ times a day for 15 days. The NO content in blood plasma was assessed by the concentration of the amount of final N0 metabolites (N03 + N02), identified by means of the photocalorimetric method.

Results: The content of (NO3 + N02) in peripheral blood of patients with CAP was slightly higher $(6.83 \pm 0.29) \mu \mathrm{mol} / \mathrm{l}$ as compared to the group of apparently healthy individuals $(5.19 \pm 0.14) \mu \mathrm{mol} / \mathrm{l}$, while in patients with CAP associated with CHD it has markedly increased to $(12.74 \pm 1.09) \mu \mathrm{mol} / \mathrm{l}$.

Against the background of administered treatment, the index of ( $\mathrm{NO3}+\mathrm{NO2})$ in patients with coronary heart disease has decreased to $(5.76 \pm 0.33) \mu \mathrm{mol} / \mathrm{l}$, while in the group of patients who were not given tivortin aspartate additionally, this index has even slightly increased $(7.01 \pm 0.40) \mu \mathrm{mol} / \mathrm{l}$.

Conclusions: Marked increase of ( $\mathrm{NO3}+\mathrm{NO2}$ ) levels in blood pointed to destabilization of the course of coronary heart disease with CAP, which was eliminated by the involvement of tivortin aspartate ( 15 days) to the main course of treatment.
\end{abstract}

KEY WORDS: Community-acquired pneumonia, coronary heart disease, Nitric oxide

Wiad Lek. 2020;73(8):1707-1711

\section{INTRODUCTION}

Respiratory diseases still remain some of the most common human ailments, accounting for the highest number of days of disability, invalidity and mortality, causing significant economic costs nationwide [1], and the first place in their structure belongs to community-acquired pneumonia (CAP). In the United States, CAP accounts for over 4.5 million outpatient and emergency visits annually, corresponding to approximately 0.4 percent of all encounters [2]. CAP is the second most common cause of hospitalization and the most common infectious cause of death [3]. Approximately 650 adults are hospitalized with CAP every year per 100,000 population in the United States, corresponding to 1.5 million cases of CAP hospitalizations each year [4]. Globally, about three million people die annually due to pneumonia, exceeding all other infectious causes of death including tuberculosis, malaria, and human immunodeficiency virus (HIV) infection [5]. In the European Union (EU), pneumonia was responsible for 118,300 deaths and the previous review reports an annual incidence of 1.08-1.7 per 1000 population in Europe [6].
One of the key factors identifying the prognosis and adverse outcome in community-acquired pneumonia is the concomitant cardiovascular disorder, including coronary heart disease (CHD) in particular. Because of high prevalence rates of $\mathrm{CHD}$ and high risk of associated complications, which lead to patients' disability and mortality, this problem bears not only medical but also social character. $\mathrm{CHD}$ occupies one of the leading places in the structure of morbidity and mortality of the population not only in Ukraine, but around the world, accounting for $>9$ million deaths in 2016 according to the World Health Organization (WHO) estimates [7].

Although CHD mortality rates worldwide have declined over the past four decades, CHD remains responsible for about one-third or more of all deaths in individuals over the age of 35 [7]. It has been estimated that nearly half of all middle-aged men and one-third of middle-aged women in the United States would develop some manifestations of $\mathrm{CHD}$ [4]. This explains growing interest towards the problem of its early diagnostics, destabilization of CHD course in community-acquired pneumonia and medicamentous 
management of triggering factors of pathophysiological changes, as well as the severity of both generalized and local myocardial hypoxia.

Nitrogen oxide (NO) compound plays an active role in antimicrobial activity in CAP and is also an inflammatory mediator, inhibits platelet and leukocyte adhesion, prevents platelet aggregation and reduces the growth of smooth muscles in vessels thus undoubtedly affecting the development of CAP [9].

NO is produced by different cells: epithelial, endothelial, neurons and is present in almost all organs and systems of the human body. The NO life-span does not exceed 6-10 seconds, after which it is converted with the involvement of oxygen and water into nitrates (NO3) and nitrites (NO2). $\mathrm{NO}$ is formed from L-arginine as a result of oxidation by oxygen with the participation of nitric oxide synthase (NOS) enzyme, which is separated in 3 isoforms: neuronal - NOS1 (nNOS), inducible (macrophage) - NOS2 (iNOS) and endothelial - NOS3 (eNOS) [10]. NOS1 and NOS3 maintain low stationary level of NO, which does not exceed a few micromoles, and a large amount of NO is produced with the involvement of NOS2, which makes up hundreds of micromoles and is maintained from several hours to a few days.

Nitric oxide causes death of many types of pathogenic microorganisms, including atypical ones. This function is implemented through two mechanisms: 1) apoptotic death of host cells, which destroys the favorable medium for the reproduction of microorganisms and disseminates the infectious process; 2 ) the release of substances toxic to the pathogen. Basically, the antimicrobial action involves the capability of reactive intermediates of nitric oxide to cause nitrosylation and deamination of proteins, leading to oxidative damage and disruption of the DNA repair system [11]. The cytotoxic effect of NO is enhanced by its ability to react with the superoxide radical, resulting in the formation of peroxynitrite (ONOO-), which has higher reactivity than $\mathrm{NO}$ or superoxide radical, and is synthesized according to the following formula: $\mathrm{H} 2 \mathrm{O} 2+\mathrm{NO}=\mathrm{ONOO}-+\mathrm{H}[12]$. Under physiological conditions, ONOO- is formed in minimal quantities. At low concentrations, ONOO may cause vascular dilatation, reduces platelet aggregation and expression of adhesive molecules, and it also has cytoprotective properties and is in fact a donor of NO.

The increase of $\mathrm{NO}$ and free radicals, which occurs in inflammatory diseases, particularly in community-acquired pneumonia, enables the synthesis of ONOO- and leads to the significant increase in its local concentration in the vascular wall [13]. At high concentrations, ONOO- is very toxic, it induces apoptosis [14], blocks prostacycline synthesis and enhances thromboxane synthesis, causes protein fragmentation due to the nitration of amino acids and lipoproteins, and thus initiates autoimmune reactions to haptens [15], induces the oxidation of low-density lipoproteins (LDL) thus leading to the formation of the most important factor that damages the NOS-3 system $[13,15]$. That is why, it is important to study the metabolism of nitric oxide associated with the progression of coronary heart disease under the conditions of community-acquired pneumonia and the possibility of medicamentous management of nitric oxide metabolic disorders, as increased concentration of NO is directly proportional to the formation of peroxynitrites.

In our opinion, the involvement of the exogenous NO donor, tivortin aspartate, in the treatment of community-acquired pneumonia associated with coronary heart disease would have a beneficial effect. The drug is a combination of arginine and aspartic acid. L-arginine aspartate is a substrate for NO synthase, an enzyme that catalyzes the synthesis of nitric oxide in endothelial cells. Aspartic acid as a nitrogen donor for transamination reactions plays an important role in protein metabolism and has a marked antihypoxic effect.

\section{THE AIM}

The aim of the study was to assess the metabolic by-products of nitric oxide in peripheral blood before and after the medicamentous management in patients suffering from community-acquired pneumonia associated with coronary heart disease.

\section{MATERIALS AND METHODS}

We have examined 102 patients with community-acquired pneumonia aged from 50 to 65 years. The diagnosis was made and verified according to the current guidelines, namely: presence of newly formed pulmonary infiltration and clinical symptoms such as cough, purulent sputum, chest pain, shortness of breath, fever or characteristic auscultatory changes. The examination revealed that 58 patients had a history of cardiovascular disease and were previously diagnosed with CHD. All the patients were administered treatment according to the order of the Ministry of Health of Ukraine No.128 of March 19, 2007. - "On approval of clinical protocols for the provision of medical care in the specialty "Pulmonology". Complex treatment of community-acquired pneumonia in the cohort of patients with coronary heart disease was supplemented by the additional use of tivortin aspartate, which is taken orally with food at the dose of $5 \mathrm{ml} \mathrm{(1g)} 3$ times a day for 15 days. The control group consisted of 17 apparently healthy individuals (AHI) with no evidence of respiratory tract disorders and other internal organ pathology.

The content of NO in blood plasma was judged by the concentration of its final stable metabolite - nitrite (NO2) and the content of the total amount of final NO metabolites (nitrates + nitrite). The method for determining the NO2 content in venous blood plasma is based on the photocalorimetric determination of the optical density of $\mathrm{NO} 2$ coloured complex with Griess reagent. Blood sample was taken from the ulnar vein using heparin as an anticoagulant. The blood was centrifuged at $2000 \mathrm{~g}$ for 5 minutes and the serum was frozen at the temperature of $-30^{\circ} \mathrm{C}$ until the investigation. After thawing, the sample of serum was deproteinized with the use of $0.5 \mathrm{~mol} / \mathrm{l}$ of sodium hydrox- 
Table 1. The total amount of terminal metabolites of nitric oxide (nitrates (N03)/nitrites (NO2)) in patients' peripheral blood ( $\mu \mathrm{mol} / \mathrm{l}$ )

\begin{tabular}{|c|c|c|}
\hline \multicolumn{3}{|c|}{ Groups of patients } \\
\hline \multirow[t]{2}{*}{ AHI, $n=17$} & \multicolumn{2}{|c|}{$\begin{array}{c}5.19 \pm 0.14 \\
(p<0.01)\end{array}$} \\
\hline & before treatment & after treatment \\
\hline Patients with community-acquired pneumonia & $\begin{array}{c}6.83 \pm 0.29 \\
(p<0.05)\end{array}$ & $\begin{array}{c}7.01 \pm 0.40 \\
(p<0.05)\end{array}$ \\
\hline $\begin{array}{l}\text { Patients with community-acquired pneumonia associated } \\
\text { with coronary heart disease }\end{array}$ & $\begin{array}{c}12.74 \pm 1.09 \\
(p<0.05)\end{array}$ & $\begin{array}{l}5.76 \pm 0.33 \\
(p<0.05)\end{array}$ \\
\hline
\end{tabular}

ide solution $(\mathrm{NaOH})$ and $100 \mathrm{~g} / \mathrm{l}$ of zinc sulfate solution $\left(\mathrm{ZnSO}_{4}\right)$. The contents of the test-tube were mixed and centrifuged for $15 \mathrm{~min}$. at $3000 \mathrm{~g}$. Since the diazotization reaction with Griess reagent is specific for NO2 only, the determination of nitrates should be carried out after their preliminary reduction. The reduction of nitrates to nitrite was performed using Nitralyzer ${ }^{\text {Th }}$ reactors (World Precision Instruments, Inc. USA) in the presence of $0.5 \mathrm{M} \mathrm{NH} 4 \mathrm{OH}$, pH 9.0 as a buffer (the ratio of plasma volume to buffer volume was 9:1). The supernatant fluid was mixed with an equal volume of Griess reagent ( $10 \mathrm{~g} / \mathrm{l}$ of sulfanilamide, 1 $\mathrm{g} / \mathrm{l}$ of naphthalenediamine, $25 \mathrm{~g} / \mathrm{l}$ of phosphoric acid) and incubated for 10 minutes at room temperature. The absorbance of the solution was measured at the wavelength of $546 \mathrm{~nm}$ on a spectrophotometer. Sodium nitrite was used as a standard and the quantitative content of nitrite in blood was determined according to the calibration curve (5-50 $\mu \mathrm{m} \mathrm{NaNO2).} \mathrm{All} \mathrm{the} \mathrm{investigations} \mathrm{were} \mathrm{conducted}$ according to a single pattern: at the time of patient's admission to the clinic and on the $21^{\text {st }}$ day from the beginning of treatment. Statistical processing of the study material was performed with the help of paired statistical methods, as well as by means of statistical difference method, using Student's t-test and dispersed analysis with the help of "Statistica 6.0" package.

\section{RESULTS AND DISCUSSION}

The investigation showed that the content of nitric oxide $(\mathrm{NO} 3+\mathrm{NO} 2)$ metabolites in peripheral blood was slightly higher $(6.83 \pm 0.29) \mu \mathrm{mol} / \mathrm{l}$

$(\mathrm{p}<0.05)$ in patients with community-acquired pneumonia as compared to the group of apparently healthy individuals $(5.19 \pm 0.14) \mu \mathrm{mol} / \mathrm{l},(\mathrm{p}<0.01)$ (Table 1). However, a marked increase in $(\mathrm{NO} 3+\mathrm{NO} 2)$ to $(12.74 \pm 1.09)$ $\mu \mathrm{mol} / \mathrm{l}(\mathrm{p}<0.05)$ was observed in the group of patients with community-acquired pneumonia associated with coronary heart disease.

The use of complex therapy, which involved the administration of tivortin aspartate for 15 days, made it possible to achieve the following results at the time of re-examination: the content of products of nitric oxide metabolism (NO3 + $\mathrm{NO} 2$ ) in peripheral blood of patients who were additionally administered tivortin aspartate has substantially decreased and nearly reached the level recorded in control group of patients and made up $(5.76 \pm 0.33) \mu \mathrm{mol} / \mathrm{l},(\mathrm{p}<0.05)$. At the same time, this index has even slightly increased in the group of patients whose complex therapy did not include the additional use of exogenous $\mathrm{NO}$ donor, and made up $(7.01 \pm 0.40) \mu \mathrm{mol} / \mathrm{l}(\mathrm{p}<0.05)$.

Oxidative stress is a major factor that damages the NO synthesis system in inflammatory diseases, including community-acquired pneumonia [16]. The main sources of free radicals during inflammation are leukocytes, as they contain NAD (P) H-oxidase capable of synthesizing cytotoxic levels of free radicals and cyclooxygenase of endothelial cells [16].

The large number of free radicals in inflammation leads to the development of endothelial dysfunction, in which the increased production of NO in the endothelium creates excellent conditions for the formation of toxic levels of ONOO- in the vascular wall [17]. The development of endothelial dysfunction results in the following: reduced synthesis and impaired NO bioavailability due to inhibition of expression or inactivation of endothelial NO synthase; increased NO degradation before reaching its site of action; decreased density of muscarinic receptors on the surface of endothelial cells, the irritation of which normally leads to NO formation; increased endothelin-1 production by endothelium and other vasoconstrictor factors; impaired endothelial integrity [17].

The damaging action of different cytokines (Interleukins-1, -6 , TNF- $\alpha$, IFN- $\gamma$ ) which attain critically high levels in patients with pulmonary inflammation may also impair the mechanism of NO synthesis and lead to the development of proatherogenic changes in vessels [18]. They activate the second NO synthesis system (NOS-2), also capable of synthesizing toxic amounts of $\mathrm{NO}$ and therefore the peroxynitrite [19]. Additionally, the synthesis of NO may be enhanced by alveolar macrophages that are activated by cytokines and bacterial endotoxins [20], as well as bronchial and alveolar epitheliocytes, mast cells, endotheliocytes and smooth muscle cells of pulmonary vessels. Accumulating in cells in inadequately large quantities, the NO molecule loses its physiological functions, becoming a substrate for ONOO- synthesis [21].

The decreased amount of NO with physiological properties reduces the control of the intensity of smooth muscle cells growth and consequently leads to myocyte proliferation, intimal growth and plaque formation. [22] Under the influence of high levels of interleukin-1 and TNF- $\alpha$, which are significantly increased in communi- 
ty-acquired pneumonia, the absence of an inhibitory effect of $\mathrm{NO}$ on endothelial cells leads to a significant increase in the expression of adhesive molecules, resulting in the so-called "homing" (accumulation) of inflammatory cells in endothelium and subendothelial space. Subsequently, macrophages capture cholesterol and various lipoproteins leading to the formation of "core" of the plaque [22] and complicates the course of coronary heart disease in this cohort of patients.

Considering the half-life of ONOO-, which is approximately 1 second [23], it can be assumed that it manages to spread from the site of its formation to a distance equal to several cellular diameters, which is fair enough to show up its specific destructive character. The disintegration of ONOO- occurs in 3 different ways, but eventually either nitrates (NO3) or nitrites (NO2) are formed [21]. That is why, there is a significant increase in the amount of (NO3 $+\mathrm{NO} 2$ ) in patients with community-acquired pneumonia associated with coronary heart disease.

Under the influence of ONOO-, oxidation of low-density lipoproteins occurs, which is considered to be one of the most important risk factors for CHD progression. Lysophosphatidylcholine is the key factor in the damage of low-density oxidized lipoproteins as it is can alter the NOS-3 endothelial synthetase system [24]. Thus, even low and moderate levels of lysophosphatidylcholine may reduce the activity and amount of synthetase. Furthermore, the reuptake of $\mathrm{L}$-arginine by endothelial cells, which is the only substrate for NO synthesis, is significantly reduced [24]. This leads to an increase in the amount of superoxide radicals and, consequently, to the synthesis of peroxynitrite, which in turn is able to activate the oxidation of low density lipoproteins, resulting in the formation of the so-called "vicious pathological circle".

Therefore, the main causes of disturbed synthesis and bioavailability of NO include: deficiency of the NO - L-arginine substrate, impaired expression of eNOS, accelerated metabolism of NO with the formation of peroxynitrite, oxidation of LDL resulting in the formation of lysophosphatidylcholine.

The use of L-arginine in patients with community-acquired pneumonia associated with coronary heart disease is substantiated by the following mechanisms: inclusion of NO into the synthesis by the arginine-oxidase conversion pathway, reduction of leukocytes adhesion to the endothelium thus improving the endothelial function, reduction of platelet aggregation thus decreasing the active formation of atherosclerotic plaque, restoration of endothelium-dependent vasodilation in atherosclerosis, decrease in the formation of oxidized low-density lipoproteins.

Nearly complete normalization of the $(\mathrm{NO} 3+\mathrm{NO} 2)$ amount in the blood of patients with community-acquired pneumonia asociated with coronary heart disease after the administration of exogenous NO donor indicates the restoration of physiological metabolism of nitric oxide, and is also alined with the data obtained by other investigations, namely - S. Saleh [25], which proved that L-arginine significantly reduces oxidative stress, including the arginine-oxidase NO conversion pathway, thus reducing the amount of peroxynitrite production.

\section{CONCLUSIONS}

The 2.45 times increase in the amount of NO metabolic by-products (nitrates (NO3) / nitrites (NO2)) in blood of patients with community-acquired pneumonia, as compared to the indices observed in control group of patients, is a clear sign of destabilization of the course of coronary heart disease in patients with CAP. Complex treatment with tivortin aspartate made it possible to eliminate the surplus of nitric oxide metabolic by-products and thus eliminate one of the risk factors for destabilization of the course of coronary heart disease in patients with community-acquired pneumonia.

\section{REFERENCES}

1. Ferkol T., Schraufnagel D. The global burden of respiratory disease. Ann Am Thorac Soc. 2014 Mar;11(3):404-6.

2. Xu J., Murphy S.L., Kochanek K.D., Bastian B.A. Deaths: Final Data for 2013. Natl Vital Stat Rep. 2016 Feb 16;64(2):1-119.

3. Pfuntner A., Wier L.M., Stocks C. Most Frequent Conditions in U.S. Hospitals, 2011. HCUP Statistical Brief \#162, Agency for Healthcare Research and Quality, Rockville, MD, September 2013.

4. Ramirez J.A., Wiemken T.L., Peyrani P., Arnold F.W., Kelley R., Mattingly W.A. et al. Adults Hospitalized With Pneumonia in the United States: Incidence, Epidemiology, and Mortality. Clin Infect Dis. 2017 Nov 13;65(11):1806-12.

5. Heo J.Y., Seo Y.B., Choi W.S., Lee J. et al. Incidence and case fatality rates of community-acquired pneumonia and pneumococcal diseases among Korean adults: Catchment population-based analysis. PLOS One. 2018;13:e0194598.

6. Torres A., Peetermans W.E., Viegi G. et al. Risk factors for community-acquired pneumonia in adults in Europe: a literature review. Thorax. 2013;68:1057-1065. doi: 10.1136/ thoraxjn-2013-204282.

7. Global Health Estimates 2016: Deaths by Cause, Age, Sex, by Country and by Region, 2000- 2016. Geneva, Switzerland: World Health Organization; 2018.

8. Benjamin E.J., Virani S.S., Callaway C.W., Chamberlain A.M. et al. Heart Disease and Stroke Statistics-2018 Update: A Report From the American Heart Association. Circulation. 201803 20;137(12):e67-e492.

9. Nathan C., Shiloh M.U. Reactive oxygen and nitrogen intermediates in the relationship between mammalian hosts and microbial pathogens. Proc Natl Acad Sci USA. 2000 Aug 1;97(16):8841-8.

10. Nathan C.T. Role of nitric oxide synthesis in macrophage antimicrobial activity. 1991(3): 65-70.

11. Beckmann J.S., Ye Y.Z., Anderson P.G., Chen J. et al. Extensive nitration of protein tyrosines in human atherosclerosis detected by immunohistochemistry. Biol Chem Hoppe Seyler. 1994; 375:81-88.

12. Beckman J.S., Beckman T.W., Chen J., Marshall P.A. Apparent hydroxyl radical production by peroxynitrite: implications for endothelial injury from nitric oxide and superoxide. Proc Natl Acad Sci USA. 1990 Feb;87(4):1620-4.

13. Tschudi M.R., Mesaros S., Lüscher T.F., Malinski T. Direct in situ measurement of nitric oxide in mesenteric resistance arteries. Increased decomposition by superoxide in hypertension. Hypertension. 1996 Jan;27(1):32-5. 
14. Maulik N., Yoshida T., Das D.K. Oxidative stress developed during the reperfusion of ischemic myocardium induces apoptosis. Free Radic Biol Med. 1998 Mar 15;24(5):869-75.

15. Liaudet L., Soriano F.G., Szabó C. Biology of nitric oxide signaling. Crit Care Med. 2000 Apr;28(4 Suppl):N37-52.

16. Loza R.C. Contribution of oxidative stress in pneumonia. Oxidative Stress and the Critically III Patient. 155-169.

17. Barnes P.J. Nitric oxide and airway disease. Ann Med. 1995 Jun;27(3):389-93.

18. Boulanger C.M., Tanner F.C., Béa M.L., Hahn A.W. et al. Oxidized low density lipoproteins induce mRNA expression and release of endothelin from human and porcine endothelium. Circ Res. 1992 Jun;70(6):1191-7.

19. Zhang H., Snead C., Catravas J.D. Nitric oxide differentially regulates induction of type II nitric oxide synthase in rat vascular smooth muscle cells versus macrophages. Arterioscler Thromb Vasc Biol. 2001 Apr;21(4):529-35.

20. Nathan C.F., Hibbs J.B. Role of nitric oxide synthesis in macrophage antimicrobial activity. Curr Opin Immunol. 1991 Feb;3(1):65-70.

21. Beckman, J.S., Beckman, T.W., Chen J., Marshall P.A. et al. Apparent Hydroxyl Radical Production by Peroxynitrite: Implications for Endothelial Injury from Nitric Oxide and Superoxide. Proceedings of the National Academy of Sciences of the United States of America. 87. 1620-4. 10.1073/pnas.87.4.1620.

22. Chartrain N.A., Geller D.A., Koty P.P., Sitrin N.F. et al. Molecular cloning, structure, and chromosomal localization of the human inducible nitric oxide synthase gene. J Biol Chem. 1994 Mar 4;269(9):6765-72.

23. Hanazawa T., Kharitonov S.A., Barnes P.J. Increased nitrotyrosine in exhaled breath condensate of patients with asthma. Am J Respir Crit Care Med. 2000 0ct;162(4 Pt 1):1273-6.

24. Eon A. Kim, Ji Ae Kim, Mi Hye Park, Sung Chul Jung et al. Lysophosphatidylcholine induces endothelial cell injury by nitric oxide production through oxidative stress, The Journal of Maternal-Fetal \& Neonatal Medicine, 22:4, 325-331, D0I: 10.1080/14767050802556075

25. Saleh S., El-Demerdash E. Protective effects of L-arginine against cisplatin-induced renal oxidative stress and toxicity: role of nitric oxide. Basic Clin Pharmacol Toxicol. 2005 Aug;97(2):91-7.

\section{ORCID and contributionship:}

Mykola M. Ostrovskyy: 0000-0002-3922-0583 ${ }^{A, F}$

Oleksandr I. Varunkiv: 0000-0002-9403-9701 A,B,D,F

Lilia Dm. Todoriko: 0000-0002-0117-6513 D,F

Iryna O. Savelikhina: 0000-0003-2219-8460 C,D

Mariana O. Kulynych-Miskiv: 0000-0001-6091-5438 C,D

Alla B. Zuban: 0000-0002-7807-5497 B,D

Olha B. Molodovets: 0000-0003-0482-3760 B,E

Kseniia M. Ostrovska: 0000-0002-2402-4539 C,D

\section{Conflict of interest:}

The Authors declare no conflict of interest.

\section{CORRESPONDIG AUTHOR \\ Oleksandr I. Varunkiv \\ Ivano-Frankivsk National Medical University \\ 2 Halytska St., 76018 Ivano-Frankivsk, Ukraine \\ tel: +38(0342)53 3295 , \\ e-mail: varunkiv.oleksandr@gmail.com}

Received: 29.10.2019

Accepted: 15.06 .2020

\footnotetext{
A - Work concept and design, B - Data collection and analysis, C - Responsibility for statistical analysis, D-Writing the article, $\mathbf{E}$-Critical review, $\mathbf{F}$ - Final approval of the article
} 